\title{
Ovarian Hormone Deficiency Reduces Intrinsic Excitability and Abolishes Acute Estrogen Sensitivity in Hippocampal CA1 Pyramidal Neurons
}

\author{
Wendy W. Wu, ${ }^{1}$ John P. Adelman, ${ }^{2}$ and James Maylie ${ }^{1}$ \\ ${ }^{1}$ Department of Obstetrics and Gynecology, and the ${ }^{2}$ Vollum Institute, Oregon Health \& Science University, Portland, Oregon 97239
}

Premature and uncompensated loss of ovarian hormones following ovariectomy (OVX) elevates the risks of cognitive impairment and dementia. These risks are prevented with estrogen $\left(\mathrm{E}_{2}\right)$-containing hormone replacement therapy initiated shortly following $0 \mathrm{VX}$ but not after substantial delay. Currently, the cellular bases underlying these clinical findings are unknown. At the cellular level, intrinsic membrane properties regulate the efficiency of synaptic inputs to initiate output action potentials (APs), thereby affecting neuronal communication, hence cognitive processing. This study tested the hypothesis that in CA1 pyramidal neurons, intrinsic membrane properties and their acute regulation by $\mathrm{E}_{2}$ require ovarian hormones for maintenance. Whole-cell current-clamp recordings were performed on neurons from $\sim 7$-month-old OVX rats that experienced either short-term ( $10 \mathrm{~d}$, control OVX) or long-term ( 5 months, $\mathrm{OVX}_{\mathrm{LT}}$ ) ovarian hormone deficiency. The results reveal that long-term hormone deficiency reduced intrinsic membrane excitability (IE) as measured by the number of evoked APs and firing duration for a given current injection. This was accompanied by AP broadening, an increased slow afterhyperpolarization (sAHP), and faster accumulation of $\mathrm{Na}_{\mathrm{V}}$ channel inactivation during repetitive firing. In the control OVX neurons, $\mathrm{E}_{2}$ acutely increased IE and reduced the sAHP. In contrast, acute regulation of IE by $\mathrm{E}_{2}$ was absent in the $\mathrm{OVX}_{\mathrm{LT}}$ neurons. Since the degree of IE of hippocampal pyramidal neurons is positively related with hippocampus-dependent learning ability, and modulation of IE is observed following successful learning, these findings provide a framework for understanding hormone deficiency-related cognitive impairment and the critical window for therapy initiation.

\section{Introduction}

Ovariectomy (OVX) for diseases and prophylaxis against ovarian cancer is performed annually on $>300,000$ women in the United States (Whiteman et al., 2008). This results in an acute decline of circulating ovarian hormones including estrogen $\left(\mathrm{E}_{2}\right)$, creating "surgical menopause," distinct from natural menopause in which the loss of hormones is gradual and takes several years to complete. While natural menopause is not associated with cognitive changes (Henderson and Sherwin, 2007), human (Nappi et al., 1999; Farrag et al., 2002; Rocca et al., 2007) and animal studies (Gibbs, 2000; Markowska and Savonenko, 2002; Daniel et al., 2006) indicate that premature and prolonged hormone deficiency following OVX negatively affects learning and memory. Further, the efficacy of $\mathrm{E}_{2}$-containing hormone replacement therapy to maintain cognitive performance declines as the postOVX interval without treatment lengthens (Sherwin, 2005). The

\footnotetext{
Received Nov. 21, 2010; revised Dec. 6, 2010; accepted Dec. 17, 2010.

This work was funded by the Office of Research on Women's Health and the National Institute of Child Health and Human Development, Oregon Health \& Science University Building Interdisciplinary Research Careers in Women's Health Grant HD043488-8 to W.W.W., National Institutes of Health (NIH) Grants NS038880 and NS065855 to J.P.A., and NIH Grant MH081860 to J.M.

Correspondence should be addressed to Wendy W. Wu, Department of Obstetrics and Gynecology, Oregon Health \& Science University, Mail Code L-458, 3181 SW Sam Jackson Park Road, Portland, OR 97239. E-mail: wuwendy@ohsu.edu.

DOI:10.1523/JNEUROSCI.6081-10.2011

Copyright $\odot 2011$ the authors $\quad 0270-6474 / 11 / 312638-11 \$ 15.00 / 0$
}

cellular bases for this impairment and the loss of $E_{2}$ efficacy are unknown.

The hippocampus is necessary for associative learning. Performance on hippocampus-dependent tasks is affected by cyclic fluctuations and pharmacological manipulations of $\mathrm{E}_{2}$ levels (Daniel et al., 1997; Fader et al., 1998; Gibbs, 2000; Korol and Kolo, 2002; Rapp et al., 2003; Korol et al., 2004). Importantly, long-term $\mathrm{E}_{2}$ deficiency through OVX results in hippocampus-dependent learning deficits (Gibbs, 2000; Markowska and Savonenko, 2002), making hippocampal neurons suitable for evaluating the consequences of hormone deficiency on mechanisms relevant for cognition. Cognitive impairment oftentimes reflects compromised neuronal communication. This can result from a change in intrinsic membrane excitability (IE), defined by intrinsic membrane properties that affect how efficiently synaptic inputs are transformed into action potentials (APs). In hippocampal CA1 pyramidal neurons, the degree of IE relates positively with ability to learn hippocampus-dependent tasks (Thibault and Landfield, 1996; Moyer et al., 2000; Tombaugh et al., 2005), and an increase in IE occurs following successful learning (Moyer et al., 1996; Thompson et al., 1996). $\mathrm{E}_{2}$ can modulate IE by altering expression of genes that determine intrinsic membrane properties, and binding directly to ion channels and receptors to alter conductances (Woolley, 2007). Therefore, a decreased IE may underlie surgical menopause-related cognitive impairment, and failure of delayed hormone replacement therapy to reverse cognitive impairment may reflect a loss of the ability of $\mathrm{E}_{2}$ to modulate IE. 
To date, experiments that evaluated the impact of long-term hormone deficiency on cellular mechanisms of learning were largely conducted on aging animals to mimic the condition of natural menopause (Gibbs, 1998; Adams et al., 2001a,b). Further, no experiments have quantified IE to determine whether or not neuronal output is altered. The impact of ovarian hormones on gene expression, neuronal morphology, activity, and cognitive processing are age-dependent (Ito et al., 1999; Adams et al., 2001a,b; Hao et al., 2007), thus limiting the applicability of results obtained from aging animals to young adults. This study therefore evaluated the impact of premature and prolonged hormone deficiency on intrinsic membrane properties of CA1 pyramidal neurons from rats representative of younger, surgically menopausal women whose cognitive functions are most severely affected by uncompensated loss of ovarian functions (Nappi et al., 1999; Rocca et al., 2007).

\section{Materials and Methods}

Subject. All animal surgeries and experiments were approved by the Institutional Animal Care and Use Committee of the Oregon Health and Science University, and conducted according to the Guide to the Care and Use of Laboratory Animals of the National Institutes of Health. In rats, uncompensated loss of ovarian hormones for $\sim 5$ months following OVX results in cognitive deficits, manifested by impaired performance on several different behavioral paradigms (Gibbs, 2000; Markowska and Savonenko, 2002; Daniel et al., 2006). These cognitive deficits are prevented with $\mathrm{E}_{2}$-containing hormone replacement therapy initiated immediately following OVX, but are not reversed when therapy is initiated after several months of delay (Gibbs, 2000; Markowska and Savonenko, 2002; Daniel et al., 2006). Thus, 5 months following OVX is a reasonable time point (1) to distinguish changes in intrinsic membrane properties that may critically alter signal processing hence cognitive function, and (2) to evaluate the cellular bases for the loss of therapy efficacy. Female F344BNF1 rats ( 2 and $\sim 7$ months old) were either sham-operated or ovariectomized to remove the peripheral source of endogenous ovarian hormones under anesthesia (using a mixture of ketamine, xylazine, and acepromazine). Rats 2-7 months old are considered young and not middle-aged, according to the definition set forth in The Physiology of Reproduction (Knobil et al., 1993). Following OVX, rats that were $\sim 7$ months old recovered in their home cages for $7 \mathrm{~d}$ (control OVX). Rats that were 2 months old either recovered in their home cages for $7 \mathrm{~d}$ or 5 months [the latter designated long-term OVX $\left(\mathrm{OVX}_{\mathrm{LT}}\right)$ ] (Fig. 1A). Increasing the in vivo $\mathrm{E}_{2}$ level before rats are killed increases structural connectivity (dendritic spine density) in the CA1 region of adult OVX rats (Woolley and McEwen, 1992). Therefore, to determine whether intrinsic membrane properties of CA1 pyramidal neurons are also sensitive to in vivo $\mathrm{E}_{2}$ level, 72 and $48 \mathrm{~h}$ before being killed control OVX and $\mathrm{OVX}_{\mathrm{LT}}$ rats were injected subcutaneously with either $10 \mu \mathrm{g}$ of $17 \beta$ estradiol benzoate $\left(E_{2}\right)$ in $100 \mu$ l of sesame oil $(O)$ or $100 \mu$ l of sesame oil alone to vary the circulating level of $\mathrm{E}_{2}$. Examining the uteri postmortem revealed that $\mathrm{E}_{2}$-injected rats in both the control OVX and the OVX groups exhibited uterine hypertrophy, while the O-injected rats exhibited uterine hypotrophy.

Hippocampal slice preparation. Rats were anesthetized with isofluorane and rapidly decapitated. The brain was rapidly removed, and $300 \mu \mathrm{m}$ slices from the left middle third of the hippocampus were cut using a vibrating microtome (VT1000S, Leica) in ice-cold artificial CSF (aCSF) of the following composition (in mM): $119 \mathrm{NaCl}, 26 \mathrm{NaHCO}_{3}, 2.5 \mathrm{KCl}, 1$ $\mathrm{NaH}_{2} \mathrm{PO}_{4}, 1.3 \mathrm{MgCl}_{2}, 2 \mathrm{CaCl}_{2}$, and 25 dextrose (saturated with a carbogen mixture of $95 \% \mathrm{O}_{2}$ and $5 \% \mathrm{CO}_{2}$ ). Slices were held in carbogensaturated aCSF at $35^{\circ} \mathrm{C}$ for $30 \mathrm{~min}$, and then at room temperature for at least $1 \mathrm{~h}$ before recording.

Electrophysiology. Experiments were performed at room temperature. Neurons were visualized using a fixed-stage, upright microscope (Axioskop FS2, Carl Zeiss) equipped with infrared differential interference contrast optics. The recording chamber was continuously superfused with carbogen-saturated aCSF flowing at a rate of $\sim 2 \mathrm{ml} / \mathrm{min}$. Patch elec- trodes, pulled from filamented borosilicate pipettes (BF150-86-10, Sutter Instruments), had a resistance of $2-3 \mathrm{M} \Omega$ when filled with the following internal solution (mM): $140 \mathrm{KMeSO}_{4}, 10 \mathrm{KCl}, 10 \mathrm{HEPES}, 2$ MgATP, $0.4 \mathrm{NaGTP}$, and 10 Tris-phosphocreatine, $\mathrm{pH}$ adjusted to 7.25 with $\mathrm{KOH}$, with a final osmolarity of $\sim 290 \mathrm{mOsm}$. Whole-cell patchclamp recordings were obtained from CA1 pyramidal neurons using a Multiclamp 700A amplifier (Molecular Devices), digitized using a Digidata 1440A interface (Molecular Devices), and transferred to a computer using pClamp10 software (Molecular Devices). In bridge mode, series resistance was electronically compensated to the point that "instantaneous" voltage jumps in response to the onset and the offset of current steps were no longer apparent. Relative to the uncompensated values determined in voltage-clamp following whole-cell formation, the degree of compensation was $>90 \%$, and series resistance did not change by $>10 \%$ throughout the experiment (bridge: start, $13.3 \pm 0.6 \mathrm{M} \Omega$; end, $14.4 \pm 0.6 \mathrm{M} \Omega$ ). The resting membrane potential (RMP) was measured $\sim 5$ min following whole-cell formation and at the end of the experiment. Neurons were maintained at $-65 \mathrm{mV}$ with a constant bias current injection throughout the experiment to normalize the basal availability of voltage-gated ion channels that regulate IE. Input resistance $\left(R_{\text {input }}\right)$ was measured as the inverse slope of the linear fit to the current steady-state voltage $\left(V_{\mathrm{ss}}\right)$ relation, assessed with a series of hyperpolarizing current steps in increments of $10 \mathrm{pA}$. The current-clamp protocol used to determine $R_{\text {input }}$ was given twice in control aCSF and twice in the presence of $\mathrm{E}_{2}, \sim 10$ and 45 min following whole-cell formation. In control aCSF, intrinsic membrane properties of CA1 pyramidal neurons determined with this internal solution remained stable for the duration of a typical experiment $(\sim 50 \mathrm{~min})$. Experiments were performed in the presence of SR95531 $(5 \mu \mathrm{M})$, CGP55845 $(2.5 \mu \mathrm{M})$, CNQX $(25 \mu \mathrm{M})$, and D-AP5 (50 $\mu \mathrm{M})$ to block inhibitory and excitatory synaptic transmission. Following a stable period of baseline recording in control aCSF, $\mathrm{E}_{2}$ (100 pM) was bath applied to access its acute effect on IE.

Drugs. SR95531, CGP55845, CNQX, and D-AP5 were purchased from Tocris Cookson; others were purchased from Sigma. CGP55845 and $\mathrm{E}_{2}$ (for bath application) were dissolved as stock solutions in DMSO. The final concentration of DMSO in aCSF was $<0.1 \%$.

Data and statistical analyses. Data were analyzed using custom macros written in IgorPro 6.1 (WaveMetrics). Statistical analyses were done using Statview (SAS Institute). Data were presented as mean \pm SEM, and compared statistically using the Mann-Whitney $U$ test, ANOVA, repeated-measures ANOVA, Fisher's PLSD post hoc test, and Spearman rank correlation test as appropriate. $p \leq 0.05$ was accepted as statistically significant. The symbols ${ }^{*}{ }^{* *}$, and ${ }^{* * *}$ in the figures denote statistical significance at $p \leq 0.05, p \leq 0.01$, and $p \leq 0.001$, respectively.

\section{Results}

Whole-cell current-clamp recordings were performed on CA1 pyramidal neurons of young adult OVX rats that experienced either short-term (10 d; control OVX) or long-term loss of ovarian functions $\left(\sim 5\right.$ months; $\left.\mathrm{OVX}_{\mathrm{LT}}\right)$ (Fig. $\left.1 A\right)$. All experiments were performed in the presence of excitatory and inhibitory synaptic blockers to characterize the intrinsic membrane properties independent of synaptic transmission.

\section{Premature and prolonged loss of ovarian hormones is associated with a decrease in IE}

IE, defined here as the propensity to generate APs in response to somatic current injection, was assessed with a series of $1 \mathrm{~s}$, incrementing depolarizing current steps from a baseline potential of $-65 \mathrm{mV}$. As illustrated by voltage traces from representative control OVX and $\mathrm{OVX}_{\mathrm{LT}}$ neurons, the $\mathrm{OVX}_{\mathrm{LT}}$ neurons fired significantly fewer APs in response to a given current amplitude than the control OVX neurons (Fig. $1 B$ ). While the range and increments of the current steps tested differed for the control OVX and the $\mathrm{OVX}_{\mathrm{LT}}$ neurons, comparisons of the number of APs evoked by the same current steps showed fewer APs fired by the OVX neurons at all current steps $\left[F_{(4,199)}=3.712 ; p<0.01\right.$; Fisher's 
PLSD, $p<0.001$ ]. Plotting the number of evoked APs as a function of current amplitude yielded an input-output (I/O) transfer relation descriptive of IE (Fig. $1 C, D)$. This difference in the firing properties was not associated with differences in the passive membrane properties, as the apparent $R_{\text {input }}$ and RMP for both groups of neurons were comparable $\left(R_{\text {input }}\right.$ : control OVX, $120.3 \pm 4.9 \mathrm{M} \Omega, n=18$ ); $\mathrm{OVX}_{\mathrm{LT}}, 118.4 \pm 8.8 \mathrm{M} \Omega, n=21$; RMP: control OVX, $-55.1 \pm 0.7 \mathrm{mV}$; $\mathrm{OVX}_{\mathrm{LT}}$, $-53.5 \pm 0.9 \mathrm{mV})$. Furthermore, the difference in IE was associated with the duration of post-OVX hormone deficiency and not the age at OVX or surgical procedure itself (Fig. 1C). IE of neurons from 2-month-old rats that were killed $7 \mathrm{~d}$ following OVX and sham-operated 7-month-old rats was not statistically different from that of the control OVX neurons, and was significantly more excitable than that of the $\mathrm{OVX}_{\mathrm{LT}}$ neurons (from rats also ovariectomized at 2 months of age).

Rats from the control OVX and the $\mathrm{OVX}_{\mathrm{LT}}$ groups received injections of either $\mathrm{E}_{2}$ or $\mathrm{O}$ before being killed. Although $\mathrm{E}_{2}$ priming resulted in uterine hypertrophy in both groups of rats, it affected neither the active nor the passive membrane properties of CA1 pyramidal neurons (see Notes). The lack of effect for $\mathrm{E}_{2}$ priming on intrinsic membrane properties is consistent with two previous reports (Wong and Moss, 1992; Woolley et al., 1997). Hence, data collected from neurons of the $\mathrm{E}_{2}$-primed and the $\mathrm{O}$-injected rats within each group were pooled.

The threshold current necessary to trigger cell firing appeared larger in the $\mathrm{OVX}_{\mathrm{LT}}$ than in the control OVX neurons (Fig. $1 C, D$ ). This was quantified by fitting individual $\mathrm{I} / \mathrm{O}$ transfer relations with single exponential functions, yielding predictions for the threshold current and the facility with which individual neurons generate additional APs in response to increasing current amplitude. The threshold current was significantly larger for the $\mathrm{OVX}_{\mathrm{LT}}$ than for the control OVX neurons (To trigger $1 \mathrm{AP}$ : control OVX, $42.3 \pm 5.1 \mathrm{pA}$; $\left.\mathrm{OVX}_{\mathrm{LT}}, 109.2 \pm 16.7 \mathrm{pA} ; p<0.005\right)$. Thereafter, the amount of current necessary to evoke an additional AP, estimated from the inverse of the initial slope of the I/O transfer function determined from the exponential fit, was also significantly larger for the $\mathrm{OVX}_{\mathrm{LT}}$ than for the control OVX neurons (control OVX, $11.1 \pm 1.3 \mathrm{pA} / \mathrm{AP} ; \mathrm{OVX}_{\mathrm{LT}}, 26.7 \pm 4.5 \mathrm{pA} / \mathrm{AP}$; $p<0.01)$. Together, these data show that following 5 months of premature ovarian hormone deficiency, CA1 pyramidal neurons exhibit a significant decrease in IE and are less likely to generate APs in response to a given strength of excitatory input signal.

The reduction in the number of evoked APs for the OVX neurons could reflect either a decrease in the mean firing rate

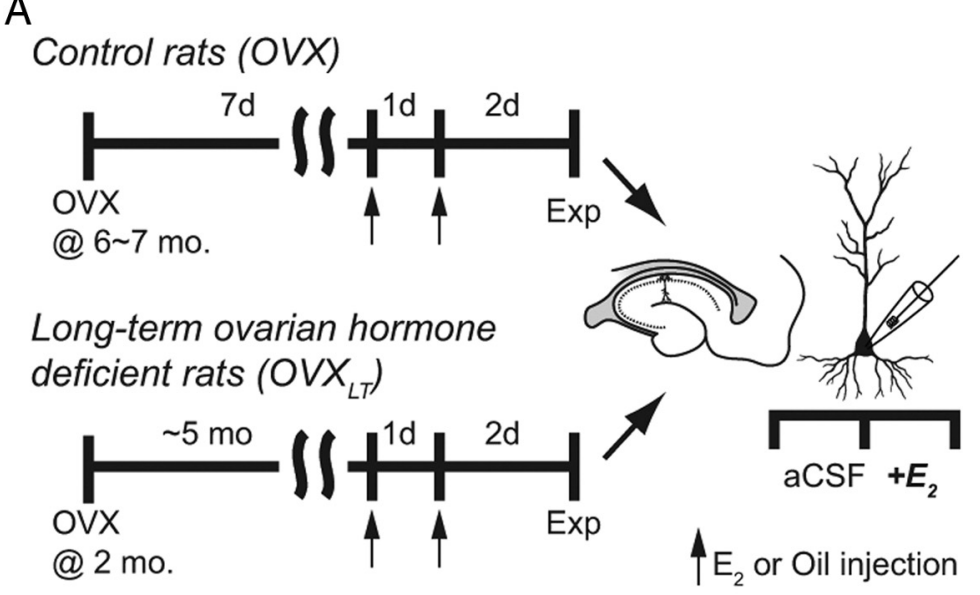

B
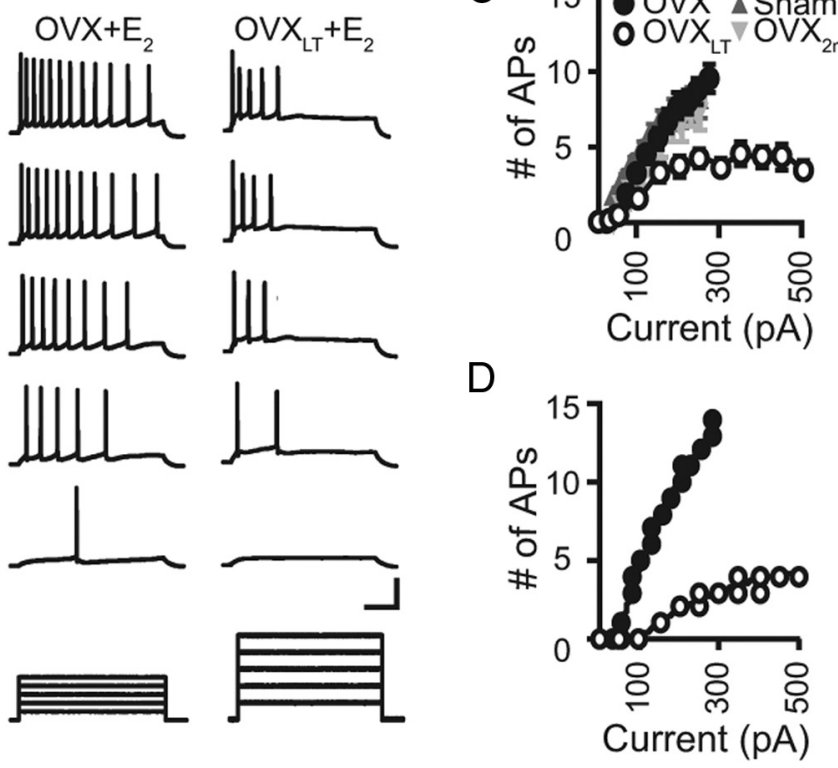

Figure 1. IE is decreased in the $0 \mathrm{VX} \mathrm{LT}_{\mathrm{T}}$ neurons. $A$, Following $0 \mathrm{VX}$, rats either recovered in their home cages for $7 \mathrm{~d}$ (control OVX) or $\sim 5$ months $\left(O \mathrm{VX}_{\mathrm{LT}}\right)$. Seventy-two and $48 \mathrm{~h}$ before electrophysiological recordings, rats were injected subcutaneously with of $E_{2}(100 \mathrm{pm})$. $\boldsymbol{B}$, Representative voltage traces from a control OVX neuron (left) and an OVX $X_{\mathrm{LT}}$ neuron (right), in response to incrementing depolarizing current steps (bottom). Voltage traces for the control OVX neuron were evoked with 50, 100, 150, 200, C, The number of evoked APs was plotted as a function of the current steps for all neurons, yielding a summary plot of the $1 / 0$ transfer relations. Data from the control OVX neurons are represented by filled black circles $(n=18)$; from the OVX $\mathrm{LT}_{\mathrm{LT}}$ neurons, open 2-month-old OVX rats, inverted light gray triangles $(n=4)$. $D$, The I/0 transfer relations of the control OVX neuron and the $0 \mathrm{VX}$ neuron shown in $\boldsymbol{B}$ fit with single exponential functions.

and/or a decrease in the ability to maintain repetitive firing. This is an important distinction, as a decreased mean firing rate suggests a decrease in the gain of the average output frequencycurrent intensity relation (a dampening of the overall neuronal response to input signals); whereas, an inability to maintain repetitive firing suggests a loss of temporal information specific to sustained excitatory input signals downstream of the hippocampus. To determine which firing pattern best describes that generated by the $\mathrm{OVX}_{\mathrm{LT}}$ neurons, the mean firing rate and the total duration of firing during the depolarizing current injection were analyzed. The mean firing rate was determined as (number of AP -1 )/duration, in which "duration" is the temporal difference between peaks of the first and the last APs in the train (Fig. $2 \mathrm{~A}$, 
A
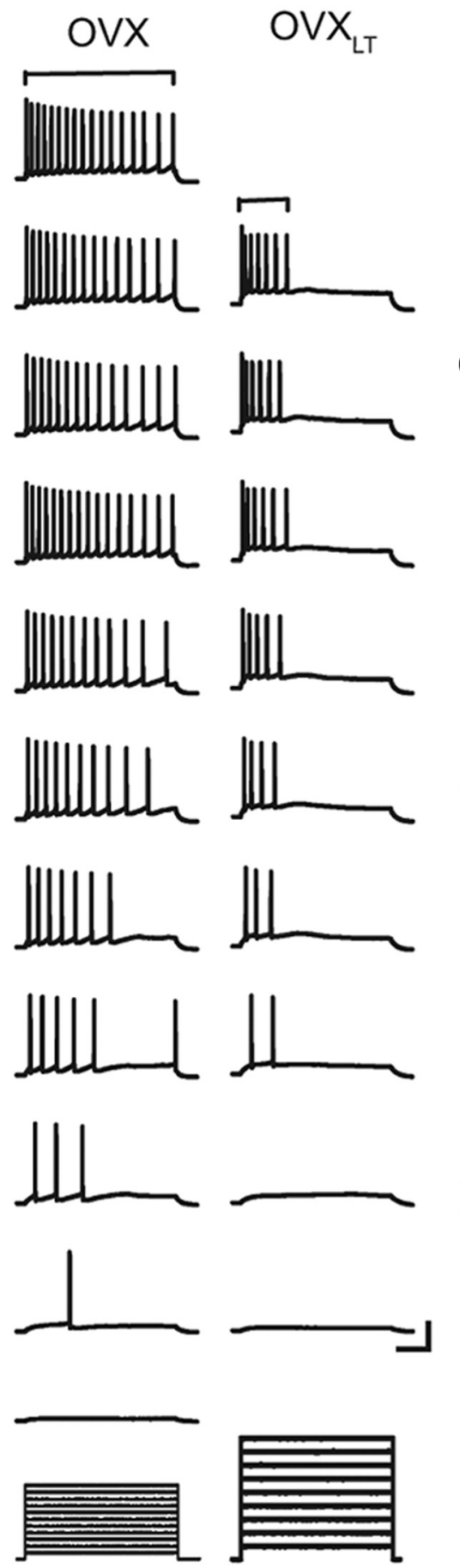

B

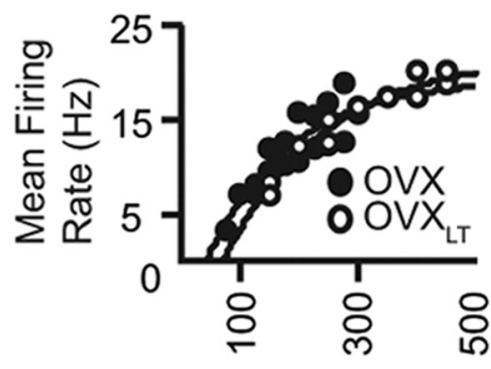

C
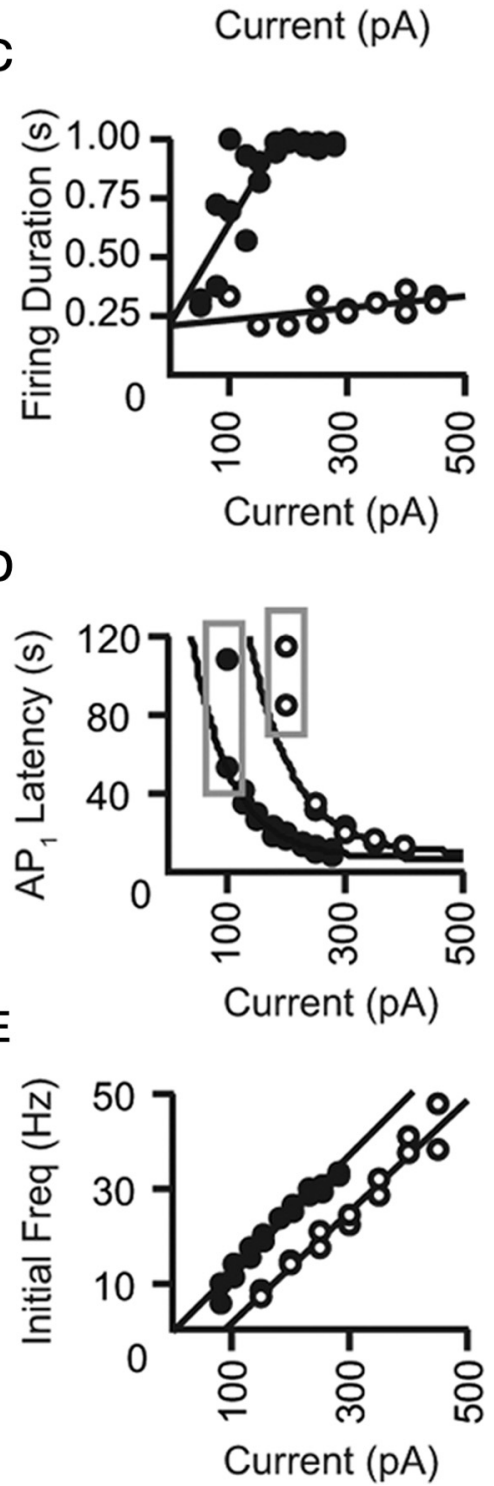

Figure 2. The $\mathrm{OVX}_{\mathrm{LT}}$ neurons are unable to maintain repetitive discharge. $A$, Representative voltage traces from a control $0 \mathrm{VX}$ neuron (left) and an $\mathrm{OVX}_{\mathrm{LT}}$ neuron (right) in response to incrementing depolarizing current steps (bottom). Voltage responses from the control OVX neuron were evoked with 50-275 pA current steps, in $25 \mathrm{pA}$ increments; from the OVX $X_{\mathrm{LT}}$ neuron, $100-450 \mathrm{pA}$ current steps, in 50 pA increments. Calibration: 40 mV or 225 pA, 200 ms. B, C, The brackets above the uppermost traces in each panel illustrate approximately how mean firing rate $(\boldsymbol{B})$ and duration of firing $(\boldsymbol{C})$ were determined for traces of different firing pattern. $\boldsymbol{B}$, Mean firing rate-current relations for the control OVX neuron (filled symbols) and the OVX shown in $\boldsymbol{A}$, fit with single exponential functions. $\boldsymbol{C}$, The firing duration- current relations for the neurons shown in $\boldsymbol{A}$. Data points excluding those that showed response saturation were fit with linear functions. $\boldsymbol{D}$, The latency of the first AP-current relations for the neurons shown in $\boldsymbol{A}$, fit with exponential functions. Data points boxed in gray were excluded from the fit. $\boldsymbol{E}$, The initial firing frequency-current relations for the neurons shown in $A$, fit with linear functions. bracketed for the uppermost two traces). Individual mean firing rate-current relations were well described by single exponential functions (Fig. 2B). On average, the predicted maximal firing rate and increase in firing rate with increasing current amplitude, derived from the initial slope of the exponential fits, were comparable for both groups of neurons (predicted maximal firing rate: control OVX, $20.9 \pm 1.2 \mathrm{~Hz} ; \mathrm{OVX}_{\mathrm{LT}}, 22.4 \pm 3.2 \mathrm{~Hz}$; initial slope: control OVX, $0.16 \pm 0.01$ $\left.\mathrm{Hz} / \mathrm{pA} ; \mathrm{OVX}_{\mathrm{LT}}, 0.15 \pm 0.01 \mathrm{~Hz} / \mathrm{pA}\right)$. However, the threshold current required to evoke two or more APs for the OVX neurons was significantly larger than that for the control OVX neurons (control OVX, $33.0 \pm 6.0$ pA; OVX $_{\mathrm{LT}}, 96.9 \pm 14.7$ $\mathrm{pA} ; p<0.001)$.

Though the threshold current amplitude was larger for the OVX $\mathrm{OVT}_{\mathrm{LT}}$ neurons, they were nevertheless capable of firing $\mathrm{AP}$ trains at mean frequencies comparable to the control OVX neurons. This suggests that the reduced output of the OVX neurons mainly reflects a decreased ability to maintain repetitive firing. Therefore, the total duration (time from current onset to the peak of the last AP) that each neuron spent firing APs during the depolarizing current step was plotted as a function of current amplitude. As illustrated in Figures $1 B$ and $2 A$, the firing duration for the control OVX neurons increased with increasing current amplitude such that eventually APs were evoked throughout the entire stimulus period. In contrast, the $\mathrm{OVX}_{\mathrm{LT}}$ neurons ceased firing much more readily than the control OVX neurons. In fact, none of the $21 \mathrm{OVX}_{\mathrm{LT}}$ neurons tested fired continuously throughout the entire stimulus period even for current steps up to $1 \mathrm{nA}$. The firing duration-current relations for the neurons presented in Figure $2 A$ are plotted in Figure $2 C$. This relation appeared linear up to the point of response saturation (defined as a $1 \mathrm{~s}$ firing duration) except for one of the $\mathrm{OVX}_{\mathrm{LT}}$ neurons, and so the growth of individual firing duration-current relations were fit with linear functions. The slope of the linear fit was significantly shallower for the $\mathrm{OVX}_{\mathrm{LT}}$ than for the control OVX neurons, highlighting the reduced ability of the $\mathrm{OVX}_{\mathrm{LT}}$ neurons to maintain repetitive firing during sustained and strong somatic depolarization (control OVX: $1.6 \pm$ $0.4 \mathrm{~ms} / \mathrm{pA}, n=18 / 18$ OVX $_{\mathrm{LT}}: 0.6 \pm 0.2$ $\mathrm{ms} / \mathrm{pA}, n=20 / 21 ; p=0.01)$.

So far, the results have described neuronal responses averaged over hundreds of milliseconds, yet the strength of excitatory input signals is also reflected by how 
A

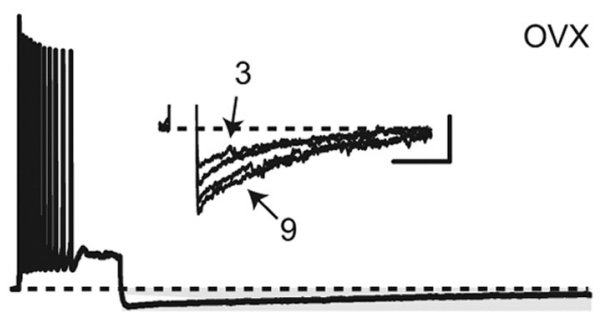

B

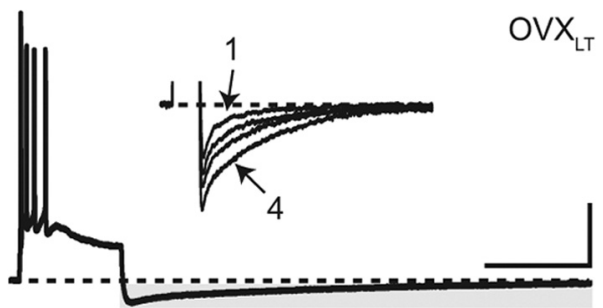

C

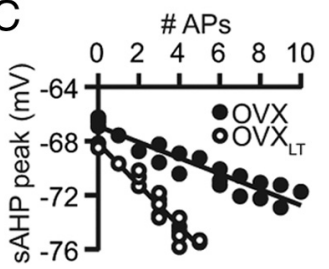

D

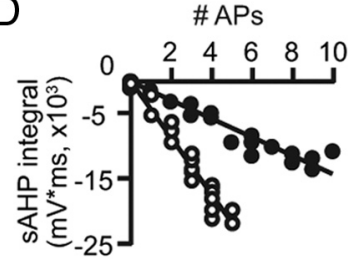

Figure 3. The $\mathrm{SAHP}$ is enhanced in the $0 \mathrm{VX}$ LT neurons. $A$, A representative voltage trace from a control OVX neuron, illustrating the SAHP (highlighted with gray shading) following a train of 11 APs. Dashed line indicates $-65 \mathrm{mV}$. Inset, The SAHPs for the same neuron associated with 3 , 5,7 , and 9 APs. APs were truncated. $B, A$ representative voltage trace from an $0 \mathrm{VX} \mathrm{LT}_{\mathrm{LT}}$ neuron, illustrating the SAHP following a train of 4 APs. Inset, The SAHPs associated with 1- 4 APs for the neuron shown in $\boldsymbol{B}$. Calibration: full voltage traces, $25 \mathrm{mV}, 1 \mathrm{~s}$; inset, $4 \mathrm{mV}, 2$ s. $\boldsymbol{C}, \boldsymbol{D}$, The sAHPs for the neurons shown in $\boldsymbol{A}$ and $\boldsymbol{B}$, measured either at the peak $(\boldsymbol{C})$ or quantified as the total integral below $-65 \mathrm{mV}(\boldsymbol{D})$, were plotted as a function of the number of evoked APs. The SAHP-AP relations were fit with linear functions. On average, the $y$-intercepts for the SAHP peak-AP linear fit were not different between the control OVX and the $0 \mathrm{VX} \mathrm{LT}_{\mathrm{T}}$ neurons (control OVX, $-67.7 \pm 0.6 \mathrm{mV} ; 0 \mathrm{VX} \mathrm{LT}_{1},-67.4 \pm 0.3 \mathrm{mV}$ ). The $y$-intercepts for the sAHP integral-AP fit for both groups were constrained to 0 .

fast an AP is generated. Therefore, the latency of the first AP in the train and the initial firing frequency versus current amplitude were plotted and compared for the control OVX and the OVX neurons. For both groups, the latency for a single AP evoked by a near-threshold $1 \mathrm{~s}$ current step was highly variable even when measured repeatedly from the same neuron (Fig. 2D, gray boxes). Hence, the latency-current analysis was restricted to responses with two or more APs. In most cases, individual first AP latency-current relations were well described by single exponential functions, and the exponential constants were not different for the control OVX and the $\mathrm{OVX}_{\mathrm{LT}}$ neurons (control OVX: $54.8 \pm 3.0 \mathrm{pA}, n=16 / 18$; $\left.\mathrm{OVX}_{\mathrm{LT}}: 70.1 \pm 8.2 \mathrm{pA}, n=19 / 21\right)$. While there appears to be a shift in the first AP latency-current relation along the current axis for the $\mathrm{OVX}_{\mathrm{LT}}$ relative to the control OVX neurons, on average this was not statistically significance $\left(\mathrm{AP}_{1}\right.$ latency of the extrapolated fit at 0 current: control OVX, $\left.271.5 \pm 34.9 \mathrm{~ms} ; \mathrm{OVX}_{\mathrm{LT}}, 423.5 \pm 67.7 \mathrm{~ms} ; p=0.09\right)$. Thus, the decreases in latency to fire (response time) with increasing current amplitude in both groups of neurons were similar. The initial firing frequency, determined from the interspike interval (ISI) between the first two APs in the train, was approximately a linear function of the current steps (Fig. 2E). On average, the slope of the linear fit was slightly but significantly smaller for the $\mathrm{OVX}_{\mathrm{LT}}$ than for the control OVX neurons, indicating a delay in generating the second $\mathrm{AP}$ for the $\mathrm{OVX}_{\mathrm{LT}}$ neurons for the same current intensity (control OVX: $0.13 \pm 0.01 \mathrm{~Hz} / \mathrm{pA}$; $\mathrm{OVX}_{\mathrm{LT}}$ : $0.10 \pm 0.01 \mathrm{~Hz} / \mathrm{pA} ; p<0.05)$. Together, these results show that the decreased IE associated with premature and prolonged loss of ovarian hormones mainly reflects an inability to maintain repetitive firing during sustained somatic depolarization rather than a decrease in the maximal firing rate of the evoked APs.

Mechanisms underlying decreased IE in the $\mathrm{OVX}_{\mathrm{LT}}$ neurons At hyperpolarized membrane potentials, hyperpolarizationactivated, nonselective cation ( $\mathrm{HCN}$ ) channels play a role in regulating IE (Maccaferri et al., 1993). HCN channel activity, inferred from the voltage "sags" in response to a series of hyperpolarizing current steps, was similar for the control OVX and the $\mathrm{OVX}_{\mathrm{LT}}$ neurons (see Notes). This finding, along with the comparable values of $R_{\text {input }}$ and RMP for the two sets of neurons, suggests that conductances active at rest are not affected by premature and uncompensated loss of ovarian functions. Thus, the drastic decrease in IE observed in the $\mathrm{OVX}_{\mathrm{LT}}$ neurons must reflect changes in conductances that are activated by somatic depolarization.

One candidate conductance underlies the postburst sAHP, a powerful negative feedback of IE in CA1 pyramidal neurons that is activated by suprathreshold somatic depolarization. The sAHP contributes to the relative refractory period following each AP, thereby regulating discharge frequency (Hotson and Prince, 1980). For both groups of neurons, the sAHP (measured at the peak or quantified as the total integral below the baseline potential) increased as a function of the number of evoked APs (Fig. 3). As shown in Figure 3, $C$ and $D$, for the representative control OVX and $\mathrm{OVX}_{\mathrm{LT}}$ neurons in Figure $3, A$ and $B$, the sAHP peak-AP relations and the SAHP integral-AP relations were well described by linear functions. On average, the slopes of both fits, reflecting the sAHP evoked per AP, were significantly larger for the $\mathrm{OVX}_{\mathrm{LT}}$ than for the control OVX neurons. This indicates an enhanced relative refractory period following each AP for the $\mathrm{OVX}_{\mathrm{LT}}$ relative to the control OVX neurons that must be overcome to generate another AP (peak/AP: control OVX, $-0.7 \pm 0.1 \mathrm{mV} / \mathrm{AP}$; $\mathrm{OVX}_{\mathrm{LT}},-1.0 \pm 0.1 \mathrm{mV} / \mathrm{AP} ; p<0.05$; Integral/AP: control OVX, $-1864.5 \pm 299.4 \mathrm{mV}^{\star} \mathrm{ms} / \mathrm{AP} ; \mathrm{OVX}_{\mathrm{LT}},-2932.1 \pm 366.0 \mathrm{mV}^{\star} \mathrm{ms} /$ AP; $p<0.05)$. On a cell-to-cell basis, the peak and the total integral of the sAHP associated with an AP were highly correlated, suggesting that both measures are dominated by the same conductance (control OVX: $r=0.906, p<0.0001$ OVX $\left._{\mathrm{LT}}: r=0.916, p<0.0001\right)$.

Also activated by somatic depolarization are the conductances that contribute to the APs themselves. Therefore, characteristics of individual AP waveforms within a train were compared. Given the voltage- and time-dependent nature of AP-associated $\mathrm{Na}_{\mathrm{V}}$ and $\mathrm{K}^{+}$conductances, one voltage trace from each neuron comprised of approximately six APs with equivalent ISIs was chosen for analysis (Fig. 4A). On average, the current step required to generate such AP trains was significantly larger for the $\mathrm{OVX}_{\mathrm{LT}}$ than for the control OVX neurons, consistent with the decreased IE in the former group (control OVX, $184.8 \pm 11.3 \mathrm{pA} ; \mathrm{OVX}_{\mathrm{LT}}$, $326.2 \pm 46.0 \mathrm{pA} ; p<0.05$ ). For successive APs across the train, the AP threshold increased and AP peak decreased more rapidly for the $\mathrm{OVX}_{\mathrm{LT}}$ than for the control OVX neurons (Fig. 4B,C). This difference suggests that there is a more rapid loss of $\mathrm{Na}_{\mathrm{V}}$ channel availability during repetitive firing for the $\mathrm{OVX}_{\mathrm{LT}}$ neurons. Due to the steep voltage dependence of $\mathrm{Na}_{\mathrm{V}}$ channel activation, the rate of rise of individual APs is determined primarily by $\mathrm{Na}_{\mathrm{V}}$ channel density and availability (Hodgkin and Huxley, 1952). Therefore, the first temporal derivative of voltage $(d V / d t)$ 
A

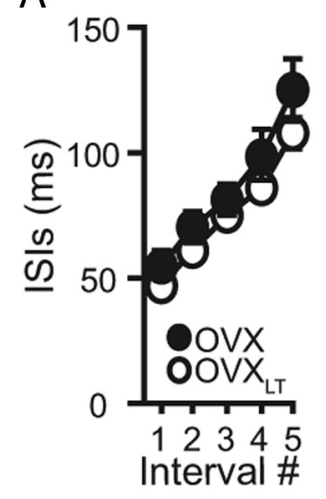

D

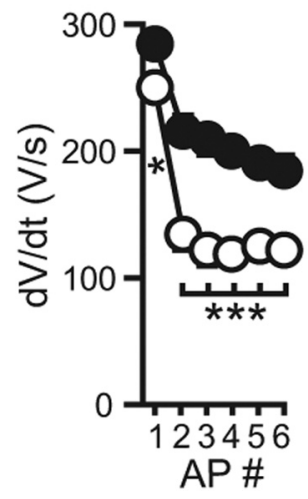

B

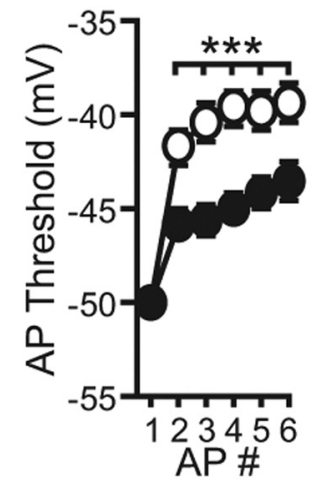

E

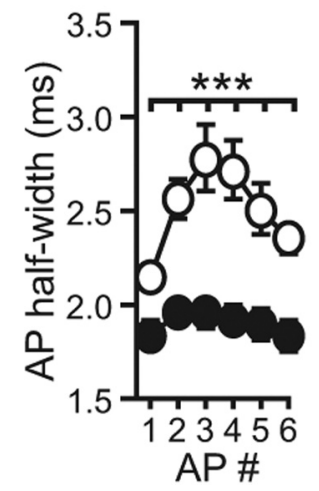

C

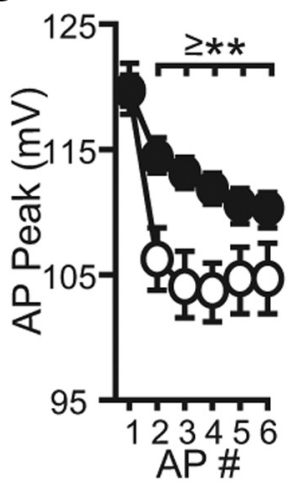

$\mathrm{F}$

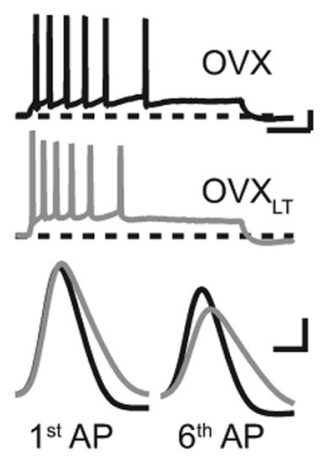

Figure 4. AP characteristics differ between the control OVX and the $0 \mathrm{VX} \mathrm{LT}_{\mathrm{LT}}$ neurons. $A$, The ISIs of successive APs for the trains selected for this analysis. $\boldsymbol{B}-\boldsymbol{E}$, Summary plots of the thresholds $(\boldsymbol{B})$, peaks $(\boldsymbol{C}), d V / d t$ values $(\boldsymbol{D})$, and half-widths $(\boldsymbol{E})$ of successive APs. $\boldsymbol{F}$, Top, Representative voltage traces from a control OVX neuron (black) and an OVX $\mathrm{LT}_{\mathrm{LT}}$ neuron (gray). Calibration: $20 \mathrm{mV}, 200$ ms. Bottom, The first and the sixth AP waveforms from the two traces shown above, expanded and superimposed. Calibration: 20 $\mathrm{mV}, 1.5 \mathrm{~ms}$.

of each AP in the train was calculated. As illustrated in Figure $4 D$, $d V / d t$ values of successive APs were smaller, and decreased more rapidly and to a greater extent across the train in the $\mathrm{OVX}_{\mathrm{LT}}$ than in the control OVX neurons. These results are consistent with a faster accumulation of $\mathrm{Na}_{\mathrm{V}}$ channel inactivation during neuronal activity for the $\mathrm{OVX}_{\mathrm{LT}}$ neurons. Since the difference in $d V / d t$ was evident in the first AP in the train, it is possible that the $\mathrm{Na}_{\mathrm{V}}$ channel density is lower in the $\mathrm{OVX}_{\mathrm{LT}}$ than in the control OVX neurons, although no difference in threshold or peak voltage for the first AP was observed (control OVX: $284.6 \pm 10.1 \mathrm{~V} / \mathrm{s}$; $\mathrm{OVX}_{\mathrm{LT}}$ : $250.6 \pm 8.8 \mathrm{~V} / \mathrm{s} ; p<0.05)$. The more rapid decrease in $d V / d t$ of successive APs in the OVX $\mathrm{LT}_{\mathrm{LT}}$ neurons is consistent with a faster accumulation of activity-dependent $\mathrm{Na}_{\mathrm{V}}$ channel inactivation, the recovery from which is also steeply voltage-dependent (Kuo and Bean, 1994). Given that the $\mathrm{OVX}_{\mathrm{LT}}$ neurons required significantly larger current steps to generate an approximate six AP train than the control OVX neurons, the steady-state membrane potentials achieved during the current step $\left(V_{s s}\right.$, the average of the last $50 \mathrm{~ms}$ of the membrane response during the current step) were compared. The $V_{\text {ss }}$ for the $\mathrm{OVX}_{\mathrm{LT}}$ neurons was on average $\sim 4 \mathrm{mV}$ more depolarized than that for the control OVX neurons (control OVX, $-52.9 \pm 0.8 \mathrm{mV}$; $\mathrm{OVX}_{\mathrm{LT}},-49.2 \pm 0.8 \mathrm{mV} ; p<$ $0.005)$. This voltage difference would contribute to a slowing of $\mathrm{Na}_{\mathrm{V}}$ channel recovery from inactivation during repetitive firing for the $\mathrm{OVX}_{\mathrm{LT}}$ neurons, and also would further enhance $\mathrm{Na}_{\mathrm{V}}$ channel inactivation (Hodgkin and Huxley, 1952).

Further examination of individual APs across the train showed that AP durations, quantified as the half-width relative to
AP threshold, were significantly broader for the $\mathrm{OVX}_{\mathrm{LT}}$ than for the control OVX neurons (Fig. $4 E, F$ ). As with $d V / d t$, AP broadening was evident in the first AP of the train without history of firing, suggesting either a decreased $\mathrm{K}^{+}$conductance that contributes to AP repolarization or an increased $\mathrm{Ca}^{2+}$ conductance that contributes to AP duration (Storm, 1987). Independent of other changes, AP broadening alone can theoretically increase the sAHP by evoking more $\mathrm{Ca}^{2+}$ influx per AP, as well as promote activity-dependent $\mathrm{Na}_{\mathrm{V}}$ channel inactivation by activating more $\mathrm{Na}_{V}$ channels during each AP. Therefore, the decreased IE in CA1 pyramidal neurons following premature and prolonged loss of ovarian functions is mediated at least by three cellular changes that are likely interrelated, as follows: (1) an increased sAHP that counters membrane depolarization; (2) a faster loss of $\mathrm{Na}_{\mathrm{V}}$ channel availability during repetitive firing; and (3) a broadening of individual APs within the AP train.

\section{$E_{2}$ acutely increases IE in the control OVX but not the $\mathrm{OVX}_{\mathrm{LT}}$ neurons}

To evaluate whether $\mathrm{E}_{2}$ acutely modulates the intrinsic membrane properties of the control OVX neurons and to determine whether premature and uncompensated loss of ovarian functions alters neuronal responses to $\mathrm{E}_{2}$, recordings were first made in control aCSF followed by bath application of $100 \mathrm{pm} \mathrm{E}_{2}$, the estimated peak serum level during proestrus in adult female rats (Smith et al., 1975).

In the control OVX neurons, bath application of $\mathrm{E}_{2}$ significantly increased the number of evoked APs for a given current step from a baseline potential of $-65 \mathrm{mV}\left[F_{(10,222)}=5.546 ; p<\right.$ $0.0001]$, resulting in a significant leftward shift in the I/O transfer relation (Fig. $5 A, B$ ). The increase in the number of evoked APs in the presence of $\mathrm{E}_{2}$ was significant for all current steps (Fisher's PLSD, $p<0.0001)$. $\mathrm{E}_{2}$ also significantly increased the $R_{\text {input }}$ and depolarized the RMP $\left(R_{\text {input }}:\right.$ aCSF, $120.3 \pm 4.9 \mathrm{M} \Omega ; \mathrm{E}_{2}, 148.6 \pm$ 7.0 M $\Omega$; $p<0.001$; RMP: aCSF, $-55.1 \pm 0.7 \mathrm{mV} ; \mathrm{E}_{2},-53.0 \pm 0.9$ $\mathrm{mV} ; p<0.01 ; n=18)$. Similarly, $\mathrm{E}_{2}$ increased IE of neurons from sham-operated rats and 2-month-old rats killed $7 \mathrm{~d}$ following OVX (Fig. 5C). In contrast, neither the I/O transfer relation (Fig. $5 D, E)$ nor the passive membrane properties of the $\mathrm{OVX}_{\mathrm{LT}}$ neurons were acutely affected by $\mathrm{E}_{2}\left(R_{\text {input }}\right.$ : aCSF, $119.0 \pm 9.6 \mathrm{M} \Omega$; $\mathrm{E}_{2}, 123.5 \pm 11.9 \mathrm{M} \Omega$; RMP: aCSF, $-53.6 \pm 1.1 \mathrm{mV} ; \mathrm{E}_{2},-54.0 \pm$ $1.1 \mathrm{mV} ; n=18)$. Thus, 5 months of premature and uncompensated loss of ovarian functions abolished the acute regulation of $\mathrm{E}_{2}$ on the intrinsic membrane properties of CA1 pyramidal neurons.

The $\mathrm{E}_{2}$-induced increase in the $R_{\text {input }}$ for the control OVX neurons could in part account for an increase in IE. To determine whether this change alone was sufficient to explain the leftwardshift in the I/O transfer relation, the number of evoked APs recorded in the presence of $\mathrm{E}_{2}$ was plotted against the "effective" current amplitude, calculated as the injected current multiplied by $\left(R_{\text {input-E2 }} / R_{\text {input-aCSF }}\right)$. While this led to a small rightward shift 
in the $\mathrm{I} / \mathrm{O}$ transfer relation acquired in the presence of $\mathrm{E}_{2}$ toward that acquired in control aCSF, it did not normalize the two curves (Fig. 5B, gray symbols). Thus, the $\mathrm{E}_{2}$-induced increase in the number of evoked APs in the control OVX neurons is mediated by conductances other than those that contribute to the RMP.

To understand how acute $\mathrm{E}_{2}$ application alters IE in the control OVX neurons, the firing patterns acquired in control aCSF were compared with those acquired following bath application of $\mathrm{E}_{2}$. On average, no change was detected in the predicted maximal firing rate, the initial slope of the fit, or the threshold current required to evoke two or more APs in the presence of $\mathrm{E}_{2}$ (predicted maximal firing rate: aCSF, $21.5 \pm 1.5 \mathrm{~Hz} ; \mathrm{E}_{2}, 19.8 \pm 0.8$ $\mathrm{Hz}$; initial slope: aCSF, $0.17 \pm 0.02 \mathrm{~Hz} /$ $\mathrm{pA} ; \mathrm{E}_{2}, 0.18 \pm 0.01 \mathrm{~Hz} / \mathrm{pA}$; threshold current: aCSF, $30.6 \pm 9.9 \mathrm{pA} ; \mathrm{E}_{2}, 20.2 \pm 5.7$ pA) (Fig. 6A). A comparison of the firing duration-current relations showed an increase in the predicted minimal firing duration but no change in the slope of the linear fit in the presence of $\mathrm{E}_{2}$ (predicted minimal firing duration: aCSF, $189.0 \pm$ $30.0 \mathrm{~ms} ; \mathrm{E}_{2}, 398.8 \pm 67.1 \mathrm{~ms} ; p<0.005$; slope: aCSF, $1.7 \pm 0.4 \mathrm{~ms} / \mathrm{pA} ; \mathrm{E}_{2}, 2.2 \pm 0.5$ $\mathrm{ms} / \mathrm{pA} ; n=17 / 18$ ) (Fig. $6 B$ ). The slope of individual initial frequency-current relations was also unaltered by $\mathrm{E}_{2}$ (control aCSF, $0.13 \pm 0.01 \mathrm{~Hz} / \mathrm{pA} ; \mathrm{E}_{2}, 0.14 \pm .0 .01$ $\mathrm{Hz} / \mathrm{pA}$ ) (Fig. 6C). However, $\mathrm{E}_{2}$ significantly decreased the exponential constant of the fit of the first AP latency-current relation by $13 \%$ (aCSF, $54.9 \pm 2.8 \mathrm{pA} ; \mathrm{E}_{2}$, $47.7 \pm 2.8 \mathrm{pA} ; p<0.05 ; n=17 / 18$ ) (Fig. $6 D)$, and correcting for the $\mathrm{E}_{2}$-induced change in the $R_{\text {input }}$ eliminated this difference $(59.8 \pm 3.6 \mathrm{pA})$. Together, these results show that $E_{2}$ acutely enhances the ability of the control OVX neurons to fire repetitively during sustain somatic depolarization independent of changes in the $R_{\text {input }}$. The increase in the $R_{\text {input }}$ in the presence of $\mathrm{E}_{2}$, however, is sufficient to account for a decrease in the response time for CAl pyramidal neurons to generate an AP.

In contrast to the control OVX neurons, $\mathrm{E}_{2}$ application minimally affected the firing pattern of the $\mathrm{OVX}_{\mathrm{LT}}$ neurons (see Notes). No change was observed in the predicted maximal firing rate, the initial slope of the fit, or the threshold current required to evoke two or more APs in the presence of $\mathrm{E}_{2}$ (predicted maximal firing rate: aCSF, $23.2 \pm 3.9 \mathrm{~Hz} ; \mathrm{E}_{2}, 25.4 \pm 3.9$ $\mathrm{Hz}$; initial slope: aCSF, $0.13 \pm 0.01 \mathrm{~Hz} / \mathrm{pA} ; \mathrm{E}_{2}, 0.12 \pm 0.02 \mathrm{~Hz} / \mathrm{pA}$; threshold current: aCSF, $131.2 \pm 28.5$ pA; $\mathrm{E}_{2}, 108.7 \pm 27.7 \mathrm{pA}$; $n=17 / 18)$. Likewise, no change was detected in the predicted minimal firing duration or the slope of the linear fit to the firing duration-current relation in the presence of $\mathrm{E}_{2}$ (minimal firing duration: aCSF, $231.6 \pm 31.6 \mathrm{~ms} ; \mathrm{E}_{2}, 290.8 \pm 48.6 \mathrm{~ms}$; slope:
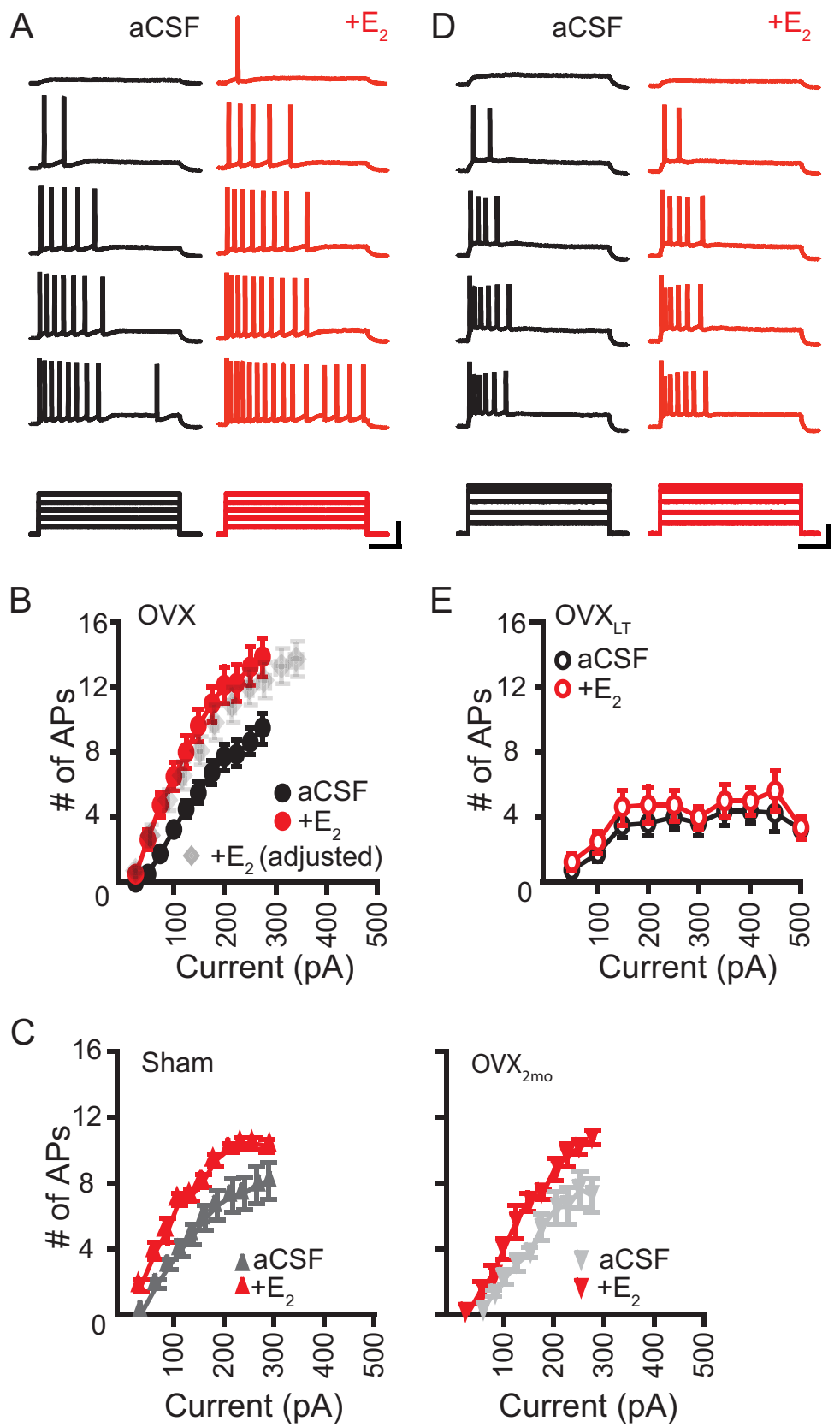

Figure 5. $E_{2}$ application increased IE in the control OVX but not the $\mathrm{OVX} \mathrm{LT}_{\mathrm{LT}}$ neurons. $A, D$, Top, representative voltage responses from a control OVX neuron $(\boldsymbol{A})$ and an $\mathrm{OVX}_{\mathrm{LT}}$ neuron $(\boldsymbol{D})$, illustrating the numbers of APs evoked by incrementing depolarizing current steps (bottom). Current amplitudes: 50, 100, 150, 200, and $250 \mathrm{pA}$ (A); 100, 200, 300, 400, and $450 \mathrm{pA}$ (D). Recordings acquired in control aCSF are shown black; in $E_{2}$, red. Calibration: $40 \mathrm{mV} ; 200 \mathrm{~ms} ; 150 \mathrm{pA}(\boldsymbol{A})$ and $200 \mathrm{pA}$ in (D). $\boldsymbol{B}, \boldsymbol{E}$, Summary plots of the I/O transfer relations for all control OVX ( $\boldsymbol{A}$, filled circles; $n=18$ ) and OVX $\mathrm{LT}_{\mathrm{LT}}$ neurons $(\boldsymbol{D}$, circles; $n=18)$. Data acquired in control aCSF are shown in black; in the presence of $E_{2}$, red. In $\boldsymbol{B}$, the numbers of evoked $A P$ s in the presence of $E_{2}$ versus the effective current steps are shown in gray. $C$, Summary plots of the $/ / 0$ transfer relations for neurons of sham-operated (left, upright triangles; $n=7$ ) and 2-month-old OVX rats (right, inverted triangles; $n=4$ ).

aCSF, $\left.0.6 \pm 0.2 \mathrm{~ms} / \mathrm{pA} ; \mathrm{E}_{2}, 0.6 \pm 0.2 \mathrm{~ms} / \mathrm{pA}\right) . \mathrm{E}_{2}$ also did not affect the exponential constant of the fit to the first AP latencycurrent relation $\left(\mathrm{aCSF}, 78.4 \pm 10.6 \mathrm{pA} ; \mathrm{E}_{2}, 86.6 \pm 11.1 \mathrm{pA} ; n=\right.$ $14 / 18$ ) or the slope of the linear fit to the initial frequency-current relation (aCSF, $0.11 \pm 0.01 \mathrm{~Hz} / \mathrm{pA} ; \mathrm{E}_{2}, 0.11 \pm .0 .01 \mathrm{~Hz} / \mathrm{pA}$ ). These results are consistent with a lack of effect of acute $\mathrm{E}_{2}$ application on the $\mathrm{I} / \mathrm{O}$ transfer relation and passive membrane properties of the $\mathrm{OVX}_{\mathrm{LT}}$ neurons.

In the control OVX neurons, bath application of $\mathrm{E}_{2}$ significantly decreased the sAHP (Fig. $7 A, B$, inset). The sAHP peak-AP 
A
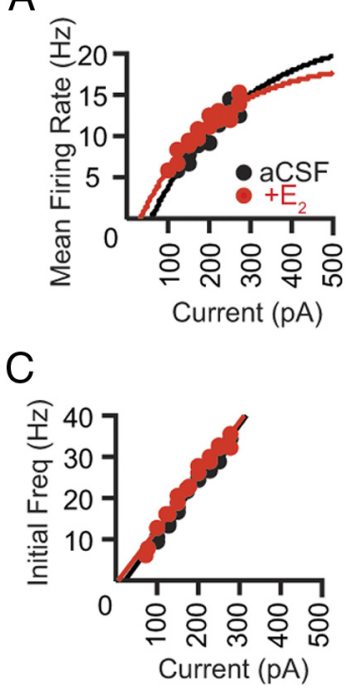

B

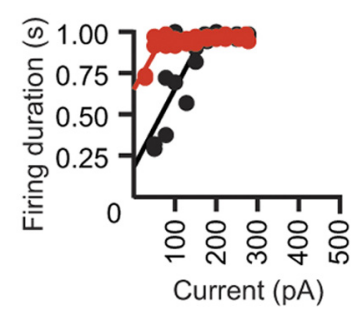

D

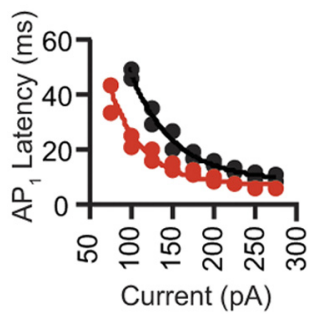

Figure 6. $E_{2}$ application decreased the latency to fire and increased firing duration in the control OVX neurons. Data acquired in control aCSF are shown in filled black symbols; following $\mathrm{E}_{2}$ application, filled red symbols. $\boldsymbol{A}$, Representative mean firing rate-current relations for a control OVX neuron, fit with single exponential functions. $\boldsymbol{B}$, Representative AP latency-current relations for a control OVX neuron, fit with single exponential functions. Data points derived from voltage traces with 1 AP only were excluded from the fit. $\boldsymbol{C}$, Representative initial firing frequency-current relations for a control OVX neuron, fit with linear functions. $D$, Representative duration of firing - current relations for a control OVX neuron, fit with linear functions. Freq., Frequency.

relations and SAHP integral-AP relations for the representative control OVX neuron shown in Figure 7, $A$ and $B$, acquired before and after $E_{2}$ application, were well described by linear functions (Fig. 7C,D). Fitting sAHP-AP relations with linear functions revealed decreases in the slopes in the presence of $\mathrm{E}_{2}$, indicating a decrease in the relative refractory period triggered by each AP and consistent with an increase in repetitive firing in the presence of $\mathrm{E}_{2}$ (peak/AP: aCSF, $-0.7 \pm 0.1 \mathrm{mV} / \mathrm{AP} ; \mathrm{E}_{2},-0.5 \pm 0.1 \mathrm{mV} / \mathrm{AP}$; $p<0.001$; integral/AP: aCSF, $-1864.5 \pm 299.4 \mathrm{mV}^{\star} \mathrm{ms} / \mathrm{AP} ; \mathrm{E}_{2}$, $\left.-1308.9 \pm 250.8 \mathrm{mV}^{\star} \mathrm{ms} / \mathrm{AP} ; p<0.001\right)$. $\mathrm{E}_{2}$ also decreased the AP half-width $\left(\mathrm{AP}_{1}\right.$ : aCSF, $1.84 \pm 0.07 \mathrm{~ms} ; \mathrm{E}_{2}, 1.78 \pm 0.07 \mathrm{~ms}$; $p<0.01$ ), which may result in a decreased influx of $\mathrm{Ca}^{2+}$ per AP, thereby in part accounting for the decreased sAHP. In contrast, the sAHPs of the $\mathrm{OVX}_{\mathrm{LT}}$ neurons were marginally affected by $\mathrm{E}_{2}$ (Fig. $7 E-H$ ). Only the AHP peak triggered per AP was slightly reduced (peak/AP: aCSF, $-1.1 \pm 0.1 \mathrm{mV} / \mathrm{AP} ; \mathrm{E}_{2},-1.0 \pm 0.1$ $\mathrm{mV} / \mathrm{AP} ; p<0.05$; integral/AP: aCSF, $-2998.1 \pm 425.8 \mathrm{mV}^{\star} \mathrm{ms} /$ AP; $\left.E_{2},-2959.5 \pm 431.1 \mathrm{mV}^{\star} \mathrm{ms} / \mathrm{AP}\right)$. However, this change did not alter the number of evoked APs across the entire range of current steps tested. Similarly, AP duration was not affected by $\mathrm{E}_{2}$ application in the $\mathrm{OVX}_{\mathrm{LT}}$ neurons $\left(\mathrm{AP}_{1}\right.$ : aCSF, $2.16 \pm 0.04 \mathrm{~ms}$; $\left.\mathrm{E}_{2}, 2.12 \pm 0.04 \mathrm{~ms}\right)$.

Altogether, this study demonstrates fundamental differences in the intrinsic membrane properties of the control OVX and the $\mathrm{OVX}_{\mathrm{LT}}$ neurons that affect their propensity to generate APs. The nearly complete loss of the ability of $\mathrm{E}_{2}$ to regulate neuronal output and passive membrane properties following long-term ovarian hormone deficiency suggests a downregulation of the cellular substrates that $\mathrm{E}_{2}$ normally acts on to control the $\mathrm{I} / \mathrm{O}$ transformation on a fast time scale, and may explain why delayed hormone replacement therapy following surgical menopause is inefficient in reversing cognitive deficits associated with uncompensated loss of ovarian function.

\section{Discussion}

This study shows that premature and prolonged loss of ovarian hormones (1) reduced the propensity of CA1 pyramidal neurons to generate APs in response to somatic depolarization, and (2) abolished the excitatory response of these neurons to $\mathrm{E}_{2}$ application. Intrinsic membrane properties affect the efficiency with which excitatory synaptic currents are transduced into APs, thereby playing a key role in regulating signal processing and information transfer between central neurons. For individual synapses, intrinsic membrane properties affect the induction and the magnitude of activitydependent plasticity such as long-term potentiation (LTP) by regulating the extent of AP back-propagation, hence the coincident detection of presynaptic and postsynaptic activities (Takahashi and Magee, 2009). Importantly, LTP at CA1 synapses mediates certain forms of hippocampus-dependent memory (Pastalkova et al., 2006; Whitlock et al., 2006). Therefore, the reduced IE in the OVX neurons may not only dampen the transfer of hippocampusprocessed information to the downstream cortical targets, but may also hinder LTP induction. Hence, a decrease in IE is likely to contribute to surgical menopause-related cognitive impairment and dementia (Rocca et al., 2007). Indeed, in aged animals, a failure in learning hippocampus-dependent temporal or spatial tasks is associated with a decreased IE in CA1 pyramidal neurons (Moyer et al., 2000; Tombaugh et al., 2005).

IE of CA1 pyramidal neurons positively relates to the ability to learn hippocampus-dependent tasks (Moyer et al., 2000; Tombaugh et al., 2005). In addition, an increased IE in hippocampal pyramidal neurons accompanies successful task acquisition (Moyer et al., 1996, 2000; Thompson et al., 1996). Importantly, pharmacological manipulations that increased IE in CA1 pyramidal neurons (Moyer et al., 1992; Oh et al., 1999) also facilitated hippocampus-dependent learning (Deyo et al., 1989; Straube et al., 1990; Kronforst-Collins et al., 1997a,b), providing a strong support for the hypothesis that modulation of IE (and neuronal output) is a key mechanism for learning and memory. The present finding that $\mathrm{E}_{2}$ application rapidly increased IE of the control OVX neurons is consistent with this hypothesis and the observations that $\mathrm{E}_{2}$ enhances hippocampus-dependent behavioral performance (Fader et al., 1998; Gibbs, 2000; Korol and Kolo, 2002; Rapp et al., 2003; Korol et al., 2004).

\section{Changes following long-term hormone deficiency}

Despite comparable passive membrane properties for the control OVX and the OVX larger depolarizing current steps to initiate firing. Once the threshold current to fire was crossed, however, the first AP latency decreased at comparable rates with increasing current intensity. These data suggest an upregulation of an outward current that operates below AP threshold to impede membrane depolarization in the $\mathrm{OVX}_{\mathrm{LT}}$ neurons. One candidate is $\mathrm{K}_{\mathrm{V}} 7 / \mathrm{KCNQ}$ channels that are active above $-60 \mathrm{mV}$ and function to delay AP generation ( $\mathrm{Hu}$ et al., 2007). A subset of $\mathrm{K}_{\mathrm{V}} 7$ channels colocalizes with $\mathrm{Na}_{\mathrm{V}}$ channels at the axon hillock, highlighting their importance in governing AP timing (Devaux et al., 2004).

Three differences in the AP waveforms were detected between the control OVX and the OVX $\mathrm{LT}_{\mathrm{LT}}$ neurons. Compared with the control OVX neurons, the OVX $\mathrm{LT}_{\mathrm{LT}}$ neurons exhibited the following: (1) an enhanced SAHP; (2) a more rapid accumulation of $\mathrm{Na}_{\mathrm{V}}$ channel inactivation during repetitive firing; and (3) broader APs. The sAHP in CA1 pyramidal neurons contributes to generate the relative refractory period following each AP. Therefore, an increased sAHP would raise the current amplitude necessary to trigger a subsequent spike as well as delay the timing of that spike, 
as observed for the $\mathrm{OVX}_{\mathrm{LT}}$ neurons. An increased sAHP alone, however, is insufficient to account for the abrupt termination of firing. The sAHP serves as a linear negative feedback activated by AP-driven $\mathrm{Ca}^{2+}$ influx. Thus, increasing the applied current amplitude should overcome the sAHP and evoke additional APs in the OVX $_{\text {LT }}$ neurons. This was not observed even for injected current up to $1 \mathrm{nA}$. Rather, these data suggest the development of an absolute refractory period mediated by $\mathrm{Na}_{\mathrm{V}}$ channel inactivation (Hodgkin and Huxley, 1952) following just approximately six evoked APs (Fig. $1 C)$. Accordingly, $d V / d t$ values of APs across the train decreased much faster and to a greater extent in the $\mathrm{OVX}_{\mathrm{LT}}$ than in the control OVX neurons. Considering the steep voltage dependence of $\mathrm{Na}_{\mathrm{V}}$ channel inactivation and recovery from inactivation, this difference can readily be attributed to the more depolarized $V_{\mathrm{ss}}$ and broader APs of the $\mathrm{OVX}_{\mathrm{LT}}$ neurons. Altogether, these data show that changes in the intrinsic membrane properties following premature and prolonged loss of ovarian hormones reflect changes in several ionic conductances that may work synergistically to reduce the output function of CA1 pyramidal neurons.

The OVX the control OVX neurons in response to a given depolarizing current step, largely reflecting a decreased ability to maintain repetitive firing during sustained somatic depolarization. Interestingly, no differences were observed in the predicted maximal firing rate and the degree that the firing rate increased with increasing current amplitude for both sets of neurons. Thus, the impact of the altered IE on the $\mathrm{OVX}_{\mathrm{LT}}$ neurons will be most apparent with longer duration, high-frequency excitatory inputs, a physiologically relevant activity pattern known to induce LTP at the CA1 synapses.

\section{Acute regulation of IE by $E_{2}$}

$\mathrm{E}_{2}$ acutely changed the active and the passive membrane properties in the control OVX neurons, indicating that $\mathrm{E}_{2}$ acts on both subthreshold active and suprathreshold-activated conductances. The increased

$R_{\text {input }}$ and the depolarized RMP in the presence of $\mathrm{E}_{2}$ may reflect suppression of a $\mathrm{K}^{+}$conductance that is active at rest such as the inwardly rectifying $\mathrm{K}^{+}$(Kubo et al., 2005) and two-pore $\mathrm{K}^{+}$"leak" channels (Enyedi and Czirjak, 2010), which are candidate targets of $\mathrm{E}_{2}$. In CA1 pyramidal neurons, the sAHP following a train of APs is dominated by the activity of slow voltage-insensitive, non-inactivating, $\mathrm{Ca}^{2+}$-activated $\mathrm{K}^{+}$channels (Lancaster and Adams, 1986) that are yet to be molecularly identified. The decrease in the sAHP in the presence of $\mathrm{E}_{2}$ may result from the suppression of the sAHP current itself and/or a decrease in $\mathrm{Ca}^{2+}$ influx through the high thresholdactivated $\mathrm{Ca}^{2+}$ channels.

The acute effects of $E_{2}$ on IE have been evaluated previously in various central neurons. The results exhibit sex and cell-type specificity, highlighting the necessity to examine the cellular consequences of the actions of $\mathrm{E}_{2}$ in a model-specific manner (Kelly et al., 1980; Nabekura et al., 1986; Minami et al., 1990). For CA1 pyramidal neurons, three electrophysiological studies have explored the effects of $\mathrm{E}_{2}$ on membrane properties and yielded discrepant findings from the present study (Wong and Moss, 1991; Kumar and Foster, 2002; Carrer et al., 2003). Using slices from both adult male and intact female rats, Wong and Moss (1991) found that $E_{2}$ increased repetitive discharge in only $20 \%$ of neurons. This increase was associated with an increased $R_{\text {input }}$ and a depolarized RMP, but not a decreased sAHP. Aside from sex and potential age differences in the rat models, differences in the recording protocols may have led to the discrepant results. In that study, intrinsic membrane properties were determined with synaptic transmission intact, and more importantly, the effect of $E_{2}$ on repetitive discharge relied on its depolarizing effect on the RMP. Depending on the $R_{\text {input }}$ of individual neurons, this may be insufficient to increase repetitive discharge. Kumar and Foster (2002) used OVX female rats of comparable age as those used in the present study and found that when the external $\left[\mathrm{Ca}^{2+}\right]$ was doubled, neurons recorded in the presence of $\mathrm{E}_{2}$ showed a smaller sAHP relative to those recorded in control aCSF. No difference was found in the passive membrane properties. In that study, rats recovered in their home cages for 8-28 d following OVX. Considering that prolonged hormone deficiency abolishes the acute effects of $\mathrm{E}_{2}$ on IE, the variability in the post-OVX recovery period in that study may account for the discrepant results. Carrer et al. (2003) found that OVX increased the sAHP current and decreased IE without affecting the passive membrane properties. However, $\mathrm{E}_{2}$ acutely decreased the SAHP current and increased IE only in rats that were deficient of ovarian hormones for 1-2 months but not in the control rats. In that study, rats underwent OVX at postnatal day 2 and were killed at 1-2 months old. Thus, the different outcomes in the present study and that by Carrer et 
al. (2003) may reflect the influences of ovarian hormones on neural circuit and cellular development.

This study used a young OVX rat model together with a physiologically relevant $\mathrm{E}_{2}$ concentration to recapitulate surgical menopause in young women. The results delineate specific changes in the intrinsic membrane properties that underlie IE of CA1 pyramidal neurons after premature and prolonged loss of ovarian hormones, as well as in the responsiveness to acute $\mathrm{E}_{2}$ exposure. These changes may be relevant to the elevated cognitive risks and loss of hormone replacement therapeutic value with time following surgical menopause, considering the association between modulation of IE and successful learning. In addition, the results indict the potential of molecular targets of $E_{2}$ that may comprise novel therapeutic targets to restore neuronal output and hence cognitive functions following surgical menopause.

\section{Notes}

Supplemental information can be downloaded from the following site: https://sites.google.com/site/sciencespotwww/home/projects/ovarianhormones-neuronal-activity/ie_cal. This material has not been peer reviewed.

\section{References}

Adams MM, Oung T, Morrison JH, Gore AC (2001a) Length of postovariectomy interval and age, but not estrogen replacement, regulate $\mathrm{N}$-methyl-D-aspartate receptor mRNA levels in the hippocampus of female rats. Exp Neurol 170:345-356.

Adams MM, Shah RA, Janssen WG, Morrison JH (2001b) Different modes of hippocampal plasticity in response to estrogen in young and aged female rats. Proc Natl Acad Sci U S A 98:8071-8076.

Carrer HF, Araque A, Buño W (2003) Estradiol regulates the slow $\mathrm{Ca}^{2+}$ activated $\mathrm{K}+$ current in hippocampal pyramidal neurons. J Neurosci 23:6338-6344.

Daniel JM, Fader AJ, Spencer AL, Dohanich GP (1997) Estrogen enhances performance of female rats during acquisition of a radial arm maze. Horm Behav 32:217-225.

Daniel JM, Hulst JL, Berbling JL (2006) Estradiol replacement enhances working memory in middle-aged rats when initiated immediately after ovariectomy but not after a long-term period of ovarian hormone deprivation. Endocrinology 147:607-614.

Devaux JJ, Kleopa KA, Cooper EC, Scherer SS (2004) KCNQ2 is a nodal $\mathrm{K}^{+}$ channel. J Neurosci 24:1236-1244.

Deyo RA, Straube KT, Disterhoft JF (1989) Nimodipine facilitates associative learning in aging rabbits. Science 243:809-811.

Enyedi P, Czirják G (2010) Molecular background of leak K+ currents: two-pore domain potassium channels. Physiol Rev 90:559-605.

Fader AJ, Hendricson AW, Dohanich GP (1998) Estrogen improves performance of reinforced T-maze alternation and prevents the amnestic effects of scopolamine administered systemically or intrahippocampally. Neurobiol Learn Mem 69:225-240.

Farrag AK, Khedr EM, Abdel-Aleem H, Rageh TA (2002) Effect of surgical menopause on cognitive functions. Dement Geriatr Cogn Disord 13:193-198.

Gibbs RB (1998) Impairment of basal forebrain cholinergic neurons associated with aging and long-term loss of ovarian function. Exp Neurol 151:289-302.

Gibbs RB (2000) Long-term treatment with estrogen and progesterone enhances acquisition of a spatial memory task by ovariectomized aged rats. Neurobiol Aging 21:107-116.

Hao J, Rapp PR, Janssen WG, Lou W, Lasley BL, Hof PR, Morrison JH (2007) Interactive effects of age and estrogen on cognition and pyramidal neurons in monkey prefrontal cortex. Proc Natl Acad Sci USA 104:11465-11470.

Henderson VW, Sherwin BB (2007) Surgical versus natural menopause: cognitive issues. Menopause 14:572-579.

Hodgkin AL, Huxley AF (1952) A quantitative description of membrane current and its application to conduction and excitation in nerve. J Physiol 117:500-544.

Hotson JR, Prince DA (1980) A calcium-activated hyperpolarization fol- lows repetitive firing in hippocampal neurons. J Neurophysiol 43:409-419.

Hu H, Vervaeke K, Storm JF (2007) M-channels (Kv7/KCNQ channels) that regulate synaptic integration, excitability, and spike pattern of CA1 pyramidal cells are located in the perisomatic region. J Neurosci 27:1853-1867.

Ito K, Skinkle KL, Hicks TP (1999) Age-dependent, steroid-specific effects of oestrogen on long-term potentiation in rat hippocampal slices. J Physiol 515:209-220.

Kelly MJ, Kuhnt U, Wuttke W (1980) Hyperpolarization of hypothalamic parvocellular neurons by 17 beta-estradiol and their identification through intracellular staining with procion yellow. Exp Brain Res 40:440-447.

Knobil E, Neill JD, Greenwald GS, Markert CK, Pfaff DW (1993) The physiology of reproduction, Ed 2. New York: Raven.

Korol DL, Kolo LL (2002) Estrogen-induced changes in place and response learning in young adult female rats. Behav Neurosci 116:411-420.

Korol DL, Malin EL, Borden KA, Busby RA, Couper-Leo J (2004) Shifts in preferred learning strategy across the estrous cycle in female rats. Horm Behav 45:330-338.

Kronforst-Collins MA, Moriearty PL, Ralph M, Becker RE, Schmidt B, Thompson LT, Disterhoft JF (1997a) Metrifonate treatment enhances acquisition of eyeblink conditioning in aging rabbits. Pharmacol Biochem Behav 56:103-110.

Kronforst-Collins MA, Moriearty PL, Schmidt B, Disterhoft JF (1997b) Metrifonate improves associative learning and retention in aging rabbits. Behav Neurosci 111:1031-1040.

Kubo Y, Adelman JP, Clapham DE, Jan LY, Karschin A, Kurachi Y, Lazdunski M, Nichols CG, Seino S, Vandenberg CA (2005) International Union of Pharmacology. LIV. Nomenclature and molecular relationships of inwardly rectifying potassium channels. Pharmacol Rev 57:509-526.

Kumar A, Foster TC (2002) 17beta-estradiol benzoate decreases the AHP amplitude in CA1 pyramidal neurons. J Neurophysiol 88:621-626.

Kuo CC, Bean BP (1994) Na+ channels must deactivate to recover from inactivation. Neuron 12:819-829.

Lancaster B, Adams PR (1986) Calcium-dependent current generating the afterhyperpolarization of hippocampal neurons. J Neurophysiol 55:1268-1282.

Maccaferri G, Mangoni M, Lazzari A, DiFrancesco D (1993) Properties of the hyperpolarization-activated current in rat hippocampal CAl pyramidal cells. J Neurophysiol 69:2129-2136.

Markowska AL, Savonenko AV (2002) Effectiveness of estrogen replacement in restoration of cognitive function after long-term estrogen withdrawal in aging rats. J Neurosci 22:10985-10995.

Minami T, Oomura Y, Nabekura J, Fukuda A (1990) 17 beta-estradiol depolarization of hypothalamic neurons is mediated by cyclic AMP. Brain Res 519:301-307.

Moyer JR Jr, Thompson LT, Black JP, Disterhoft JF (1992) Nimodipine increases excitability of rabbit CA1 pyramidal neurons in an age- and concentration-dependent manner. J Neurophysiol 68:2100-2109.

Moyer JR Jr, Thompson LT, Disterhoft JF (1996) Trace eyeblink conditioning increases CA1 excitability in a transient and learning-specific manner. J Neurosci 16:5536-5546.

Moyer JR Jr, Power JM, Thompson LT, Disterhoft JF (2000) Increased excitability of aged rabbit CA1 neurons after trace eyeblink conditioning. J Neurosci 20:5476-5482.

Nabekura J, Oomura Y, Minami T, Mizuno Y, Fukuda A (1986) Mechanism of the rapid effect of 17 beta-estradiol on medial amygdala neurons. Science 233:226-228.

Nappi RE, Sinforiani E, Mauri M, Bono G, Polatti F, Nappi G (1999) Memory functioning at menopause: impact of age in ovariectomized women. Gynecol Obstet Invest 47:29-36.

Oh MM, Power JM, Thompson LT, Moriearty PL, Disterhoft JF (1999) Metrifonate increases neuronal excitability in CAl pyramidal neurons from both young and aging rabbit hippocampus. J Neurosci 19:1814-1823.

Pastalkova E, Serrano P, Pinkhasova D, Wallace E, Fenton AA, Sacktor TC (2006) Storage of spatial information by the maintenance mechanism of LTP. Science 313:1141-1144.

Rapp PR, Morrison JH, Roberts JA (2003) Cyclic estrogen replacement improves cognitive function in aged ovariectomized rhesus monkeys. J Neurosci 23:5708-5714. 
Rocca WA, Bower JH, Maraganore DM, Ahlskog JE, Grossardt BR, de Andrade M, Melton LJ 3rd (2007) Increased risk of cognitive impairment or dementia in women who underwent oophorectomy before menopause. Neurology 69:1074-1083.

Sherwin BB (2005) Estrogen and memory in women: how can we reconcile the findings? Horm Behav 47:371-375.

Smith MS, Freeman ME, Neill JD (1975) The control of progesterone secretion during the estrous cycle and early pseudopregnancy in the rat: prolactin, gonadotropin and steroid levels associated with rescue of the corpus luteum of pseudopregnancy. Endocrinology 96:219-226.

Storm JF (1987) Action potential repolarization and a fast afterhyperpolarization in rat hippocampal pyramidal cells. J Physiol 385:733-759.

Straube KT, Deyo RA, Moyer JR Jr, Disterhoft JF (1990) Dietary nimodipine improves associative learning in aging rabbits. Neurobiol Aging 11:659-661.

Takahashi H, Magee JC (2009) Pathway interactions and synaptic plasticity in the dendritic tuft regions of CA1 pyramidal neurons. Neuron 62:102-111.

Thibault O, Landfield PW (1996) Increase in single L-type calcium channels in hippocampal neurons during aging. Science 272:1017-1020.

Thompson LT, Moyer JR Jr, Disterhoft JF (1996) Transient changes in excitability of rabbit CA3 neurons with a time course appropriate to support memory consolidation. J Neurophysiol 76:1836-1849.
Tombaugh GC, Rowe WB, Rose GM (2005) The slow afterhyperpolarization in hippocampal CA1 neurons covaries with spatial learning ability in aged Fisher 344 rats. J Neurosci 25:2609-2616.

Whiteman MK, Hillis SD, Jamieson DJ, Morrow B, Podgornik MN, Brett KM, Marchbanks PA (2008) Inpatient hysterectomy surveillance in the United States, 2000-2004. Am J Obstet Gynecol 198:34.e1-7.

Whitlock JR, Heynen AJ, Shuler MG, Bear MF (2006) Learning induces long-term potentiation in the hippocampus. Science 313:1093-1097.

Wong M, Moss RL (1991) Electrophysiological evidence for a rapid membrane action of the gonadal steroid, 17 beta-estradiol, on CA1 pyramidal neurons of the rat hippocampus. Brain Res 543:148-152.

Wong M, Moss RL (1992) Long-term and short-term electrophysiological effects of estrogen on the synaptic properties of hippocampal CA1 neurons. J Neurosci 12:3217-3225.

Woolley CS (2007) Acute effects of estrogen on neuronal physiology. Annu Rev Pharmacol Toxicol 47:657-680.

Woolley CS, McEwen BS (1992) Estradiol mediates fluctuation in hippocampal synapse density during the estrous cycle in the adult rat. J Neurosci 12:2549-2554.

Woolley CS, Weiland NG, McEwen BS, Schwartzkroin PA (1997) Estradiol increases the sensitivity of hippocampal CA1 pyramidal cells to NMDA receptor-mediated synaptic input: correlation with dendritic spine density. J Neurosci 17:1848-1859. 